\title{
HYDRODYNAMIC RESISTANCE OF CONCENTRATION POLARIZATION BOUNDARY LAYERS IN ULTRAFILTRATION
}

\author{
J.G. WIJMANS, S. NAKAO*, J.W.A. VAN DEN BERG, F.R. TROELSTRA and \\ C.A. SMOLDERS \\ Department of Chemical Technology, Twente University of Technology, P.O. Box 217 , \\ 7500 AE Enschede (The Netherlands)
}

(Received April 23, 1984; accepted in revised form August 9, 1984)

\section{Summary}

The influence of concentration polarization on the permeate flux in the ultrafiltration of aqueous Dextran T70 solutions can be described by (i) the osmotic pressure model and (ii) the boundary layer resistance model. In the latter model the hydrodynamic resistance of the non-gelled boundary layer is computed using permeability data of the Dextran molecules obtained by sedimentation experiments. It is shown both in theory and experiment that the two models are equivalent.

\section{Introduction}

In membrane filtration processes the permeate fluxes are smaller than the pure solvent fluxes in practically all cases. A number of phenomena has been suggested to account for this flux reduction: (i) a decrease of the hydraulic driving force by an osmotic pressure, (ii) the resistance of the concentration polarization boundary layer, (iii) the resistance of a gel layer, (iv) an increase in membrane resistance by plugging of the pores, and (v) the resistance of an adsorption layer. When the membrane shows a perfect, or almost perfect, rejection of the solute(s), plugging of the pores will be negligible and for many nonprotein solutes, adsorption at the membrane surface is practically absent. We will therefore concentrate in this paper on the first three phenomena mentioned above.

Theoretical considerations will show that in most ultrafiltration separation processes the phenomena (i) (osmotic pressure) and (ii) (resistance of concentration polarization boundary layer) are equivalent. This can be verified by ultrafiltration experiments with Dextran T70 solutions. The resistance of the concentration polarization boundary layer (called the boundary layer from now on) is calculated with the help of the solvent permeability of the

\footnotetext{
*Present address: Institute of Industrial Science, University of Tokyo, 7-22-1 Roppongi, Minatoku, Tokyo 106, Japan.
} 
Dextran molecules. Following Mijnlieff and Jaspers [1] this permeability is determined by sedimentation experiments.

\section{Theory}

Mass balance in the boundary layer

Due to rejection of the solute at the membrane surface, the solute concentration near that surface will increase. As a result of the concentration gradient thus generated, solute molecules will diffuse away from the membrane surface. In a cross flow membrane filtration process a steady state is reached when the convection of solute molecules towards the membrane is equal to the diffusion of solute molecules back to the bulk of the solution, see Fig. 1. When the rejection of the solute is $100 \%$, the solute molecules have a velocity relative to the membrane equal to zero. In a solute-fixed or membrane-fixed frame of reference, the diffusion equation for the solvent reads:

$c_{0} U_{0}=-D^{1} \frac{\mathrm{d} c_{0}}{\mathrm{~d} x}$

where $c_{0}$ is the solvent concentration $(\mathrm{g} / \mathrm{ml}), U_{0}$ is the solvent velocity relative to the membrane, $D^{1}$ is the mutual diffusion coefficient in the solutefixed frame and $x$ is the coordinate perpendicular to the membrane surface. The subscript 0 refers to the solvent, whereas the subscript 1 will refer to the solute.

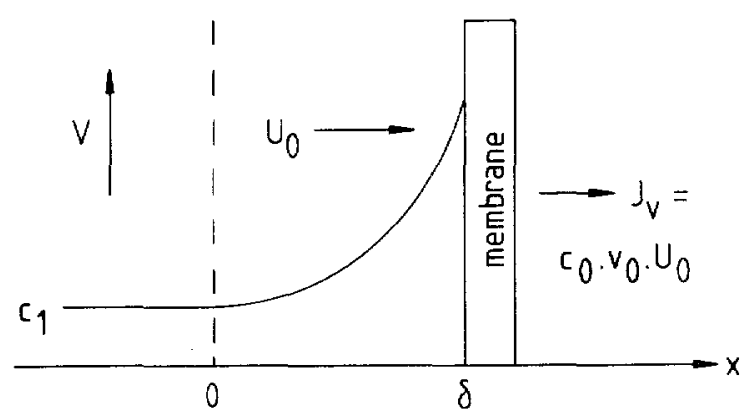

Fig. 1. Schematic representation of the phenomenon of polarization in a cross flow system. $V$ is the axial bulk velocity and $\delta$ is the boundary layer thickness.

The diffusion coefficient is generally defined and measured within a meanvolume-velocity-fixed frame of reference. If we denote the latter diffusivity as $D$, then the following relation exists [2] :

$D^{1}=\frac{D}{c_{1} v_{1}}$ 
Since $c_{0} v_{0}+c_{1} v_{1}=1$, where $v$ is the specific volume $(\mathrm{ml} / \mathrm{g})$ we have:

$\mathrm{d} c_{0}=-\frac{v_{1}}{v_{0}} \mathrm{~d} c_{1}$

and since the permeate volume flow $J_{v}=c_{0} v_{0} U_{0}$, we can rewrite eqn. (1) as:

$c_{1} J_{\mathrm{v}}=D \frac{\mathrm{d} c_{1}}{\mathrm{~d} x}$

Equation (4) is the well known concentration polarization equation and the derivation given above clearly shows that the diffusion coefficient to be used in this equation is the volume-fixed coefficient, $D$.

Application of the film model for the mass transfer near the membrane surface gives the boundary conditions for eqn. (4):

$$
\begin{array}{ll}
x=0 ; & c_{1}=c_{\mathrm{b}} \\
x=\delta ; & c_{1}=c_{\mathrm{m}}
\end{array}
$$

The boundary layer thickness, $\delta$, is the quotient of $D$ and the mass transfer coefficient $k$. The value of the diffusion coefficient depends on concentration; hence, it will vary over the boundary layer thickness and an averaged value for $D$ must be used. Integration of eqn. (4) under the condition that $J_{v}$ is constant (steady state) yields:

$c_{\mathrm{m}}=c_{\mathrm{b}} \exp \left(J_{\mathrm{v}} / k\right)$

Force balance in the boundary layer

Up to here, we have evaluated the mass balance of the boundary layer. In the stationary boundary layer there is also a force balance: the net force acting on each particle is zero. The solute molecules in the boundary layer are subject to a thermodynamic force directed to the bulk of the solution due to the gradient in their chemical potential. The force balance implies that the drag force exerted by the solvent flow on the solute molecules per gram of solute, $F_{1}$, is equal to

$F_{1}=\frac{\mathrm{d} \mu_{1}}{\mathrm{~d} x}=\frac{\mathrm{d} \mu_{1}^{\mathrm{c}}}{\mathrm{d} x}+v_{1} \frac{\mathrm{d} P}{\mathrm{~d} x}$

where $\mu$ is the chemical potential per gram, $\mu^{c}$ is the concentration part of the chemical potential and $P$ is the hydraulic pressure. In eqn. (7) it is assumed that only concentration and pressure gradients are present in the boundary layer. The balance of the drag forces yields for the drag force exerted by the solute molecules on the solvent flow per gram solvent, $F_{0}$ :

$c_{0} F_{0}+c_{1} F_{1}=0$ 
This drag force, $F_{0}$, is balanced in turn by the force due to the chemical potential gradient of the solvent, so:

$F_{0}=\frac{\mathrm{d} \mu_{0}}{\mathrm{~d} x}=\frac{\mathrm{d} \mu_{0}^{\mathrm{c}}}{\mathrm{d} x}+v_{0} \frac{\mathrm{d} P}{\mathrm{~d} x}$

The Gibbs-Duhem relation reads:

$c_{0} \mathrm{~d} \mu_{0}^{\mathrm{c}}+c_{1} \mathrm{~d} \mu_{1}^{\mathrm{c}}=0$

and inserting eqns. (7) and (9) into eqn. (8) and applying eqn. (10) we obtain:

$c_{0} v_{0} \frac{\mathrm{d} P}{\mathrm{~d} x}+c_{1} v_{1} \frac{\mathrm{d} P}{\mathrm{~d} x}=0$

From eqn. (11) it is clear that

$\frac{\mathrm{d} P}{\mathrm{~d} x}=0$

which means that in the boundary layer there is no pressure drop. The solvent flow is subject to a hydrodynamic boundary layer resistance but the energy dissipation in this layer is exactly compensated by the decrease in the chemical potential of the solvent due to its concentration gradient. Equations (8) and (12) are valid only if the complete boundary layer has the properties of a Newtonian fluid. Viscoelastic behaviour in the boundary layer or formation of a gel layer will give rize to a pressure drop outside the membrane.

Dejmek [3] was the first to analyze the force balance in a concentration polarization layer, but he did not reach the conclusion that the pressure drop in the boundary layer was zero. Wales [4] showed clearly that $\mathrm{d} P / \mathrm{d} x=0$, using an approach somewhat different from that used by us. Wales restricted his analysis to laminar boundary layers. In his opinion there is no assurance that $\mathrm{d} P / \mathrm{d} x=0$ in turbulent boundary layers where, as well as molecular diffusion, eddy diffusion is also operative. Contrary to this view, we think that in turbulent flow systems also the pressure drop in the boundary layer is zero. We have two arguments for this: (i) in the analysis given above no diffusion coefficient was used, and (ii) in the film theory for mass transfer the boundary layer is evaluated as a stagnant layer with a thickness $\delta$, which is determined by both the molecular and eddy diffusivity.

\section{Hydrodynamic resistance of the boundary layer}

The boundary layer in ultrafiltration can be seen as a stagnant, concentrated polymer solution through which the solvent permeates. For polymer concentrations exceeding the "overlap" concentration, where the individual domains of the polymer molecules touch each other, the solvent molecules have to flow through the polymer coils. In more dilute solutions the solvent flow takes place mainly around the polymer coils. According to Mijnlieff and 
Jaspers [1] the permeability of such a stagnant polymer solution can be calculated from a totally different experimental situation: sedimentation in an analytical ultracentrifuge cell. This follows from their analysis of the flow equations for sedimentation and permeation; they have obtained:

$p=\frac{\eta_{0} s}{c_{1}\left(1-v_{1} / v_{0}\right)}$

where $s$ is the sedimentation coefficient of the polymeric solute and $\eta_{0}$ is the dynamic viscosity of the solvent. The permeability, $p$, has been defined by Darcy [5] and remembering that in the boundary layer the osmotic pressure gradient is the driving force for the solvent flow, see Fig. 2, we have:

$J_{v}=\frac{\rho}{\eta_{0}} \frac{\mathrm{d} \Pi}{\mathrm{d} x}$

Integration of eqn. (14) over the thickness of the boundary layer yields:

$J_{v}=\frac{\Delta \Pi_{\mathrm{bl}}}{\eta_{0} \int_{0}^{\delta} p^{-1} \mathrm{~d} x}$

where $\Delta \Pi_{b l}$ is the osmotic pressure difference over the boundary layer. The permeability depends on the concentration and since there is a concentration profile in the boundary layer, the permeability will be a function of the coordinate $x$. Thus, the hydrodynamic resistance of the boundary layer, $R_{\mathrm{bl}}$, is defined as:

$R_{\mathrm{bl}}=\int_{0}^{\delta} p(x)^{-1} \mathrm{~d} x$

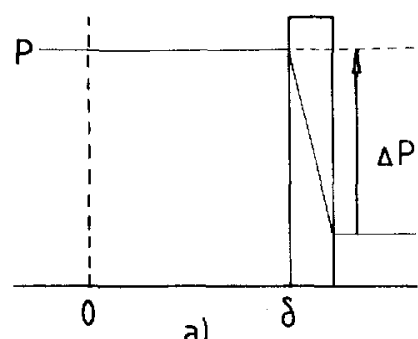

a)

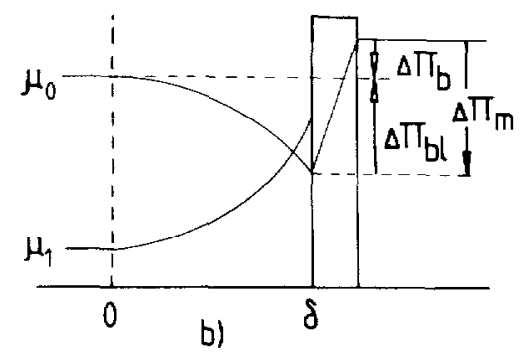

b)

Fig. 2. Gradients of pressure (a) and chemical potential (b) in and near the membrane in an ultrafiltration process.

Expression for the permeate flux

In the preceeding sections we have shown that, although the boundary layer is responsible for a hydrodynamic resistance, there is no drop in hydraulic 
pressure over the boundary layer. According to Fig. 2 there are two different but equivalent ways to describe the permeate volume flux:

$J_{\mathrm{v}}=\frac{1}{\eta_{0}} \frac{\Delta P-\Delta \Pi_{\mathrm{m}}}{R_{\mathrm{m}}}$,

and

$J_{\mathrm{v}}=\frac{1}{\eta_{0}} \frac{\Delta P-\Delta \Pi_{\mathrm{b}}}{R_{\mathrm{m}}+R_{\mathrm{bl}}}$

$\Delta P$ is the applied hydraulic pressure difference and $R_{\mathrm{m}}$ is the membrane resistance. $\Delta \Pi_{\mathrm{b}}$ and $\Delta \Pi_{\mathrm{m}}$ are osmotic pressure differences due to differences in the chemical potential:

$\mathrm{d} I \mathrm{I}=-\frac{1}{v_{0}} \mathrm{~d} \mu_{0}^{\mathrm{c}}$

or

$\Delta \Pi=-\frac{1}{v_{0}} \Delta \mu_{0}^{\mathrm{e}}$

A relation that can be obtained from eqns. (17) and (18) is:

$J_{\mathrm{v}}=\frac{1}{\eta_{\mathrm{o}}} \frac{\Delta \Pi_{\mathrm{bl}}}{R_{\mathrm{bl}}}$

Equation (20) is identical with eqn. (15) and holds for every steady-state boundary layer. In contrast with the eqns. (17) and (18), eqn. (20) is not suited for the calculation of the permeate flux since it is not an independent relation. We will return to this in the following section.

In most ultrafiltration applications, the osmotic pressure difference between the bulk of the feed solution and the permeate will be very small, so

$\Delta \Pi_{\mathrm{b}} \ll \Delta \Pi_{\mathrm{bl}}$

$\Delta \Pi_{\mathrm{b}} \ll \Delta P$

$\Delta \Pi_{\mathrm{m}} \simeq \Delta \Pi_{\mathbf{b l}}$

According to eqn. (21) we can rewrite eqn. (18) as follows:

$J_{\mathrm{v}}=\frac{1}{\eta_{0}} \frac{\Delta P}{R_{\mathrm{m}}+R_{\mathrm{bl}}}$

Equation (22) represents the "boundary layer resistance" model, while eqn. (17) is the representative of the "osmotic pressure" model. They both hold for a non-gel polarized situation. If gel formation does occur, the resistance of the gel layer must be added to the membrane resistance in eqns. (17), (18) 
and (22). It is emphasized here that if one uses the osmotic pressure model, one implicitly assumes that $\mathrm{d} P / \mathrm{d} x=0$ in the boundary layer.

Relationship between permeation, diffusion and osmotic pressure

Comparing eqn. (4) with eqn. (14) we see that there must exist a relationship between diffusivity, permeability and the dependency of the osmotic pressure on concentration. The relation between sedimentation and diffusion is given by the Svedberg equation [6]:

$D=\frac{s c_{1}}{\left(1-v_{1} \rho\right)} \frac{\mathrm{d} \mu_{1}^{\mathrm{c}}}{\mathrm{d} c_{1}}$

Here, $\rho$ is the density of the solution $\left(\rho=c_{0}+c_{1}\right)$. With the help of eqns. (10) and (19) and using

$\left(1-v_{1} \rho\right)=v_{0} c_{0}\left(1-v_{1} / v_{0}\right)$

we obtain

$D=\frac{s}{\left(1-v_{1} / v_{0}\right)} \frac{\mathrm{d} \Pi}{\mathrm{d} c_{1}}$

Substitution of eqn. (13) into eqn. (25) yields:

$D=\frac{c_{1} p}{\eta_{0}} \frac{\mathrm{d} \Pi}{\mathrm{d} c_{1}}$

This relation between diffusivity and permeability makes eqns. (4) and (14) equivalent. Mijnlieff and Jaspers [1] previously pointed out that there is one basic phenomenological relation which describes permeation, sedimentation and diffusion, and eqn. (26) is the result of this connection.

The interdependency of permeability and diffusion coefficient has also been investigated by McDonnell and Jamieson [7]. The expression obtained by them differs from our eqn. (26) by a factor $\rho v_{0}$, which originates from the fact that they have used the diffusion equation of the mass-fixed reference frame instead of the volume-fixed reference frame.

\section{Experimental}

\section{Ultrafiltration}

The ultrafiltration experiments were carried out in a thin channel cell using solutions of Dextran T70 (Pharmacia, $M_{\mathrm{n}}=36,200$ and $M_{\mathrm{w}}=70,300$ ) in water (ultrafiltrated, demineralized) as the feed. The cell had an effective membrane width of $60 \mathrm{~mm}$ and a channel height of $5.9 \mathrm{~mm}$. The membrane area length was $100 \mathrm{~mm}$ and the length of the entrance region was $250 \mathrm{~mm}$. The membranes used were Kalle polysulfone membranes of the Nadir type. The experimental set-up is shown in Fig. 3; the experimental procedure was as follows: 
1. The membrane was compacted at $\Delta P=600 \mathrm{kPa}$ for at least $50 \mathrm{hr}$ in order to obtain a time-independent water flux.

2. The pure water flux was measured at three different pressures and at three different bulk velocities.

3. A certain amount of concentrated Dextran T70 solution was added to the system, after which the system was given $60 \mathrm{~min}$ to mix.

4. The permeate flux was measured at three different pressures (lowest pressure difference first) 15 minutes after the pressure had been set.

5. Step 4 was carried out for three different axial bulk velocities (highest velocity first).

6 . The sequence of steps $3-5$ was repeated twice, so the permeate flux was measured at three different bulk concentrations (lowest concentration first).

The solute concentration in the feed and the permeate were measured by a Beckman model $915 \mathrm{~A}$ total organic carbon analyzer. The temperature was maintained at $25^{\circ} \mathrm{C}$ in all experiments.

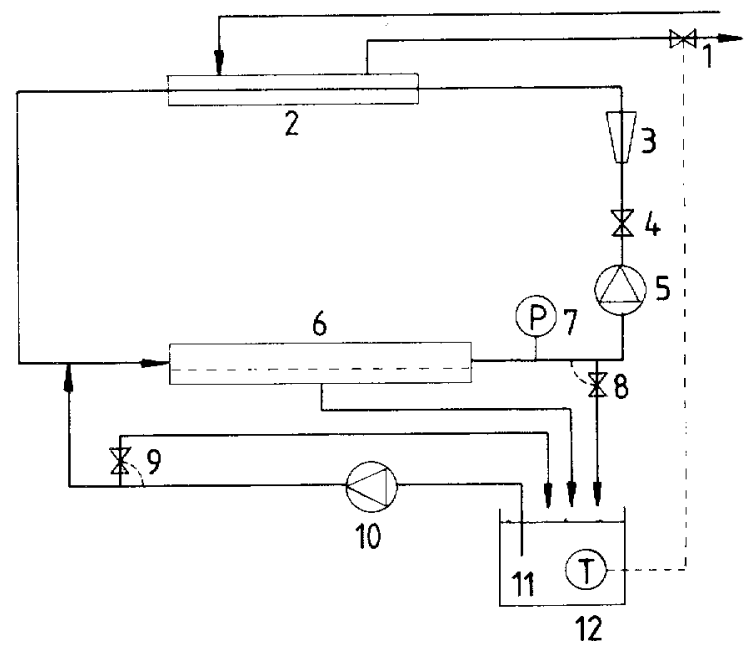

Fig. 3. Schematic representation of the ultrafiltration device: $1:$ valve cooling water; 2 : 2 : heat exchanger; 3 : flow meter; 4 : valve; 5 : recirculation pump; 6 : filtration cell; 7 : manometer; 8 : back pressure valve; 9 : back pressure valve; 10 : injection pump; 11 : feed stock solution; 12 : thermistor.

\section{Osmotic pressure}

Although the ultrafiltration experiments were carried out using Dextran T70 as the solute, the investigations into the properties of Dextran solutions were performed using both Dextran T70 and Dextran T500 (Pharmacia, $M_{\mathrm{n}}=119,500$ and $\left.M_{\mathrm{w}}=465,000\right)$. In all cases the experiments with T70 were performed at $25^{\circ} \mathrm{C}$ and those with $\mathrm{T} 500$ at $20^{\circ} \mathrm{C}$. The osmotic pressure of the Dextran solutions relative to pure water were measured with a high 
pressure osmometer [8]. The membranes used in the osmometer were Sartorius "allerfeinst".

\section{Sedimentation coefficient}

Sedimentation experiments were performed with a Beckman-Spinco Model $\mathrm{E}$ analytical ultracentrifuge. The sedimentation coefficients were determined at different concentrations from the displacement of the maximum of the concentration gradient curve.

In order to calculate the permeability from the sedimentation coefficient, the specific volume of the Dextrans in water had to be known. This quantity was calculated from the slope of the solution density versus concentration plot. Densities were measured with a Paar digital precision density meter, model DMA 50.

\section{Diffusion coefficient}

The diffusion coefficients were determined by the boundary layer broadening method using a synthetic boundary cell of the ultracentrifuge mentioned above. The concentration difference at the boundary at the beginning of each experiment was at the most $0.026 \mathrm{~g} / \mathrm{ml}$ and smaller than $0.01 \mathrm{~g} / \mathrm{ml}$ in most cases. The concentrations mentioned further on are the mean concentrations. The diffusion coefficients obtained with this kind of experiment are the volumefixed diffusion coefficients.

\section{Results and discussion}

\section{Osmotic pressure}

The osmotic pressure data for both Dextran T70 and T500 are given in Fig. 4. The osmotic pressure in a broad concentration range is conveniently represented by the general form [9]:

$\Delta \Pi=A_{1} c_{1}+A_{2} c_{1}^{2}+A_{3} c_{1}^{3}$

A least squares fit to the experimental data of Fig. 4 gives:

T70: $\Delta \Pi=0.375 c_{1}+7.52 c_{1}^{2}+76.4 c_{1}^{3}\left(10^{5} \mathrm{~Pa}\right)$
T500: $\Delta \Pi=0.0867 c_{1}+2.98 c_{1}^{2}+89.8 c_{1}^{3}\left(10^{5} \mathrm{~Pa}\right)$

According to van 't Hoff's law, the coefficient $A_{1}$ of eqn. (27) must be equal to $R T / M_{\mathrm{n}}$. The values of $R T / M_{\mathrm{n}}$ are 0.684 and $0.204 \times 10^{5} \mathrm{~Pa}-\mathrm{ml} / \mathrm{g}$ for T70 and $T 500$, respectively, so there is a substantial deviation. The origin for this deviation is probably that the osmotic experiments were carried out with concentrations larger than $0.05 \mathrm{~g} / \mathrm{ml}$. Equation (27) reduces to the van ' $t$ Hoff law in very dilute solutions only. Since we are interested in the osmotic pressure of more concentrated solutions, eqns. (28) and (29) are used to express the concentration dependence of $\Delta \Pi$. From Fig. 4 it is clear that the influence of $M_{\mathrm{n}}$ on the osmotic pressure is relatively small for concentrated solutions. 


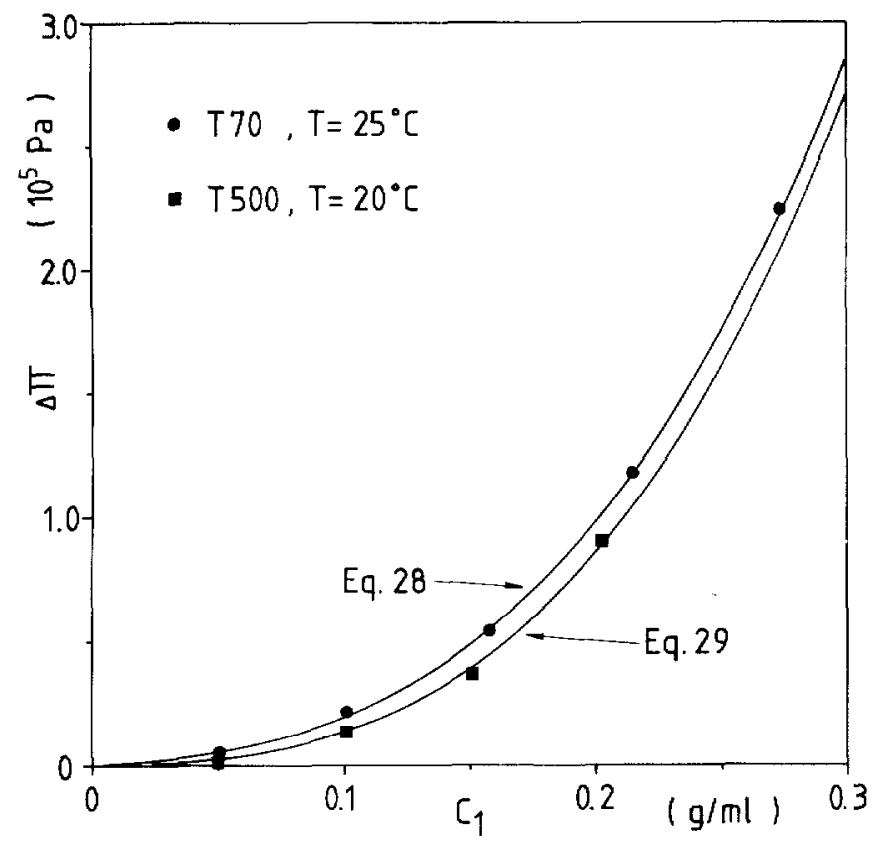

Fig. 4. Osmotic pressure of Dextran solutions relative to pure water.

\section{Sedimentation coefficient}

The sedimentation coefficients for T70 are plotted in Fig. 5 together with literature data on T70 [10] and T500 [11]. The experiment with T70 at a temperature of $20^{\circ} \mathrm{C}$ indicates that the sedimentation coefficient depends only slightly on temperature. Consistent with this observation is the fact that the sedimentation coefficients of T70 and T500, measured at $25^{\circ} \mathrm{C}$ and $20^{\circ} \mathrm{C}$ respectively, are identical for concentrations larger than $0.04 \mathrm{~g} / \mathrm{ml}$. The latter concentration is the overlap concentration of Dextran T70 in water. The data of Brown et al. [10] were measured with a Dextran T70 fraction with $M_{\mathrm{n}}=$ 44,000 and $M_{\mathrm{w}}=64,000$ and they agree very well with our experiments.

The concentration dependence of the sedimentation coefficient is usually expressed as:

$$
\frac{1}{s}=\frac{1}{s_{0}}\left(1+K_{1} c_{1}+K_{2} c_{1}^{2}\right)
$$

The coefficients $s_{0}$ and $K_{1}$ have been determined as a function of the molecular weight, $M_{\mathrm{w}}$, of Dextran fractions by a number of authors [12-14]. Using these values, a least squares fit to the experimental data gives the value for the coefficient $K_{2}$ :

$\mathrm{T} 70: \quad \frac{1}{s}=\frac{1}{3.3 \times 10^{-13}}\left(1+32.0 c_{1}+258.0 c_{1}^{2}\right) \quad\left(\sec ^{-1}\right)$ 
T500: $\frac{1}{s}=\frac{1}{8.5 \times 10^{-13}}\left(1+106.0 c_{1}+617.0 c_{1}^{2}\right)\left(\mathrm{sec}^{-1}\right)$

In the fitting procedure, the data obtained at concentrations larger than 0.04 $\mathrm{g} / \mathrm{ml}$ have been used for both Dextran fractions. Equation (31) is quite satisfactory as appears from Fig. 5. Equation (32) agrees well with the experimental data for concentrations larger than $0.02 \mathrm{~g} / \mathrm{ml}$. However, at lower concentrations there is a significant difference and therefore the least squares method was applied to obtain values for all three coefficients:

$\mathrm{T} 500: \frac{1}{s}=\frac{1}{5.06 \times 10^{-13}}\left(1+43.2 c_{1}+500.8 c_{1}^{2}\right) \quad\left(\mathrm{sec}^{-1}\right)$

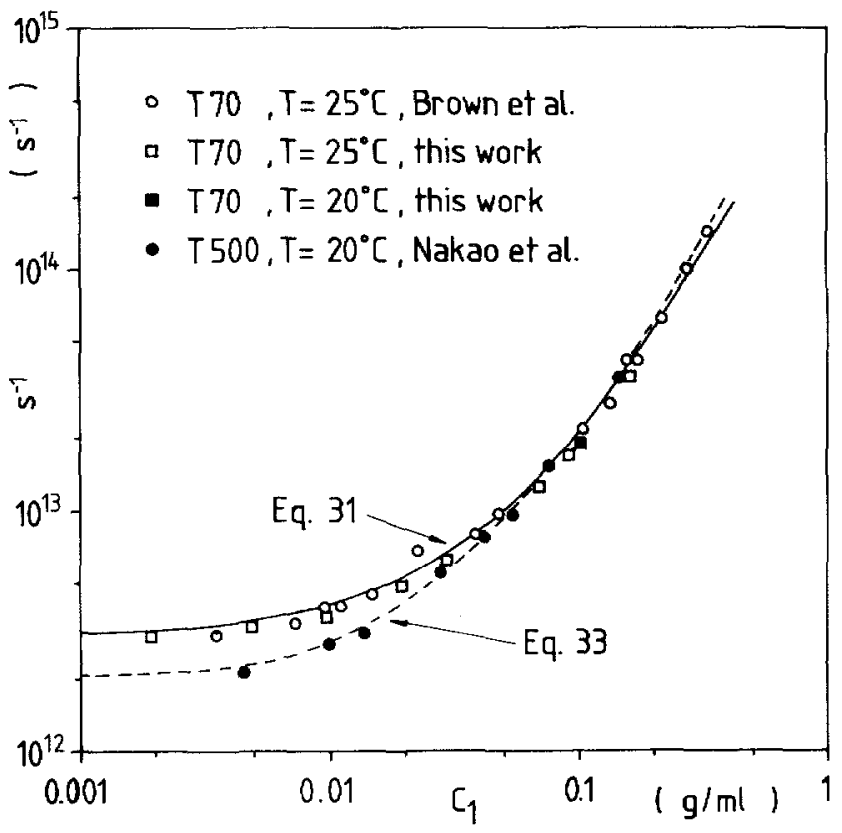

Fig. 5. Sedimentation coefficients of Dextran in water.

The partial specific volume of T70 and T500 in water appears to be concentration independent in the experimental concentration range (up to $0.3 \mathrm{~g} / \mathrm{ml})$ and has a value of $0.644 \mathrm{ml} / \mathrm{g}\left(T=25^{\circ} \mathrm{C}\right)$ and $0.625 \mathrm{ml} / \mathrm{g}\left(T=20^{\circ} \mathrm{C}\right)$, respectively.

\section{Diffusion coefficient}

The diffusion coefficients of T70 and T500 are given in Fig. 6. For Dextran T70 data obtained by Clifton [15] are included. Clifton used the following relation to express his data: 
T70: $D=5.96 \times 10^{-11}+2.12 \times 10^{-11} \tanh \left(28.4 c_{1}-1.491\right)\left(\mathrm{m}^{2} / \mathrm{sec}\right)$

and eqn. (34) agrees well with our results.

Since we performed osmotic and sedimentation experiments, we are able to calculate diffusion coefficients through the Svedberg equation. Combining eqns. (25), (27) and (30) we obtain:

$D=\frac{s_{0}\left(A_{1}+2 A_{2} c_{1}+3 A_{3} c_{1}^{2}\right)}{\left(1-v_{1} / v_{0}\right)\left(1+K_{1} c_{1}+K_{2} c_{1}^{2}\right)}$

The broken lines in Fig. 6 are calculated using eqn. (35). Although the calculated and experimental values do not match exactly, we think the agreement is remarkable. Equation (35) predicts the right order of magnitude of the diffusion coefficient and represents fairly well its concentration dependence.

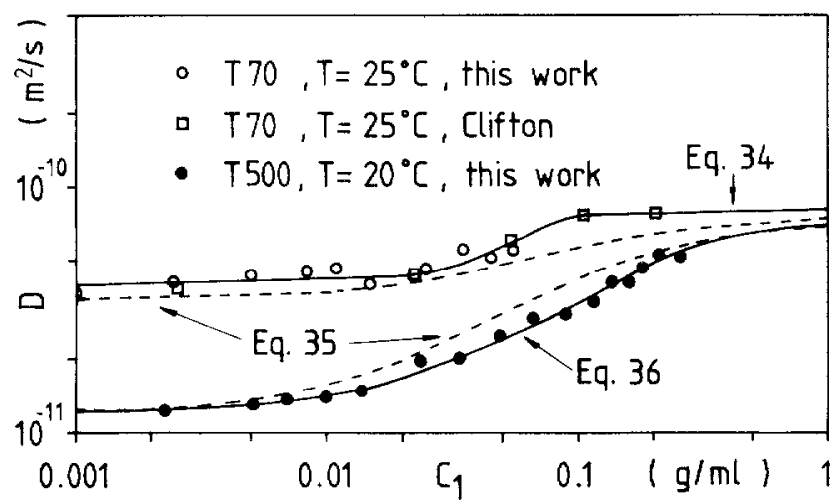

Fig. 6. Mutual diffusion coefficients of Dextran and water.

The diffusion data for Dextran T500 cannot be described by a formula similar to eqn. (34). A least squares fit to the data using a second-order or a third-order polynomial gives anomalous results for high concentrations: the diffusion coefficient decreases (second order) or increases (third order) very rapidly at concentrations exceeding $0.5 \mathrm{~g} / \mathrm{ml}$. In view of the results for Dextran T70 and of the curves drawn according to eqn. (35), we think this is very improbable. We therefore suggest the following relation to represent the diffusion data of Dextran T500:

T500: $D=1.204 \times 10^{-11}+2.614 \times 10^{-10}$

$$
-4.167 \times 10^{-10} c_{1}^{2}+2.132 \times 10^{-10} c_{1}^{3} \quad\left(\mathrm{~m}^{2} / \mathrm{sec}\right)
$$

Equation (36) is obtained by a least squares fit to the experimental data extended with two points calculated by means of eqn. (35): $D=6.5 \times 10^{-11}$ $\mathrm{m}^{2} / \mathrm{sec}$ at $c_{1}=0.5 \mathrm{~g} / \mathrm{ml}$ and $D=7.0 \times 10^{-11} \mathrm{~m}^{2} / \mathrm{sec}$ at $c_{1}=1.0 \mathrm{~g} / \mathrm{ml}$. 


\section{Ultrafiltration}

The permeate flux versus applied pressure data obtained with the ultrafiltration experiments are represented in Fig. 7. The permeate flux increases with increasing pressure, although the slope of the $J_{v}$ versus $\Delta P$ plot decreases with increasing $\Delta P$. The slope does not become zero ("limiting flux") under the circumstances studied. Furthermore, the permeate flux decreases with an increasing bulk concentration and with a decreasing axial bulk velocity. All this is in full accordance with the osmotic pressure model for ultrafiltration [16]. The rejection of the T70 molecules by the membrane decreased with increasing pressure, with an increasing bulk concentration and with a decreasing axial velocity. The lowest rejection value was $96 \%$ and the rejection was higher than $98 \%$ in all but three experiments.

Pure water flux increased linearly with $\Delta P$ and thus the membrane resistance was independent of the applied pressure and did not vary with the axial velocity. This indicates that fouling of the membrane by the ultrafiltrated water did not occur and that $R_{\mathrm{m}}$ has a constant value of $6.94 \times 10^{12} \mathrm{~m}^{-1}$.

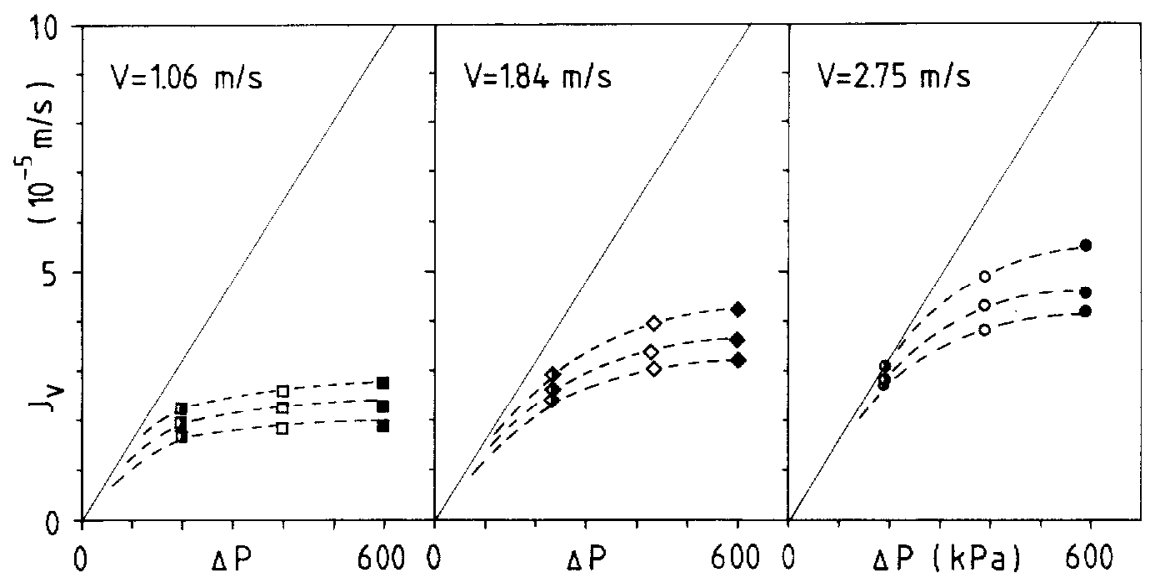

Fig. 7. Ultrafiltration permeate fluxes as a function of applied pressure, axial bulk velocity and bulk concentration. The bulk concentrations are $0.000430,0.000935$ and 0.00142 $\mathrm{g} / \mathrm{ml} ;-$ : pure water flux.

\section{Resistance of the boundary layer}

The resistance of the boundary layer can be computed from Fig. 7 using eqn. (22). This experimental value for $R_{\mathrm{bl}}$, denoted $R_{\mathrm{bl}}^{\exp }$, will be compared with the value calculated from eqn. (16) using the sedimentation and diffusion data. The expression for this $R_{\mathrm{bl}}^{\text {calc }}$ is derived as follows.

According to eqn. (13) and (30) we express the permeability of the dissolved Dextran molecules as:

$p\left(c_{1}\right)=\frac{\eta_{0} s_{0}}{\left(1-v_{1} / v_{0}\right)\left(c_{1}+K_{1} c_{1}^{2}+K_{2} c_{1}^{3}\right)}$ 
The concentration of the solute in the boundary layer is a function of the coordinate $x$ and since the rejection is almost $100 \%$ we write, see eqn. (6):

$c_{1}(x)=c_{\mathrm{b}} \exp \left(J_{v} x / D\right)$

Substitution of eqn. (38) into eqn. (37) yields:

$$
\begin{aligned}
p(x)^{-1}= & \frac{1-v_{1} / v_{0}}{\eta_{0} s_{0}}\left[c_{\mathrm{b}} \exp \left(J_{\mathrm{v}} x / D\right)\right. \\
& \left.+K_{1} c_{\mathrm{b}}^{2} \exp \left(2 J_{\mathrm{v}} x / D\right)+K_{2} c_{\mathrm{b}}^{3} \exp \left(3 J_{\mathrm{v}} x / D\right)\right]
\end{aligned}
$$

The quantity $p(x)^{-1}$ must be integrated over the boundary layer thickness, $\delta$, and since

$$
\begin{aligned}
c_{\mathrm{b}}^{\mathrm{n}} \int_{0}^{\delta} \exp \left(n J_{\mathrm{v}} x / D\right) \mathrm{d} x & =\frac{D}{J_{\mathrm{v}} n} c_{\mathrm{b}}^{\mathrm{n}}\left[\exp \left(n J_{\mathrm{v}} / k\right)-1\right] \\
& =\frac{D}{J_{\mathrm{v}} n}\left(c_{\mathrm{m}}^{\mathrm{n}}-c_{\mathrm{b}}^{\mathrm{n}}\right)
\end{aligned}
$$

we obtain

$$
\begin{aligned}
R_{\mathrm{bl}}^{\text {calc }} & =\int_{0}^{\delta} p(x)^{-1} \mathrm{~d} x \\
& =\frac{D}{J_{\mathrm{v}}} \frac{1-v_{1} / v_{0}}{\eta_{0} s_{0}}\left[c_{m}-c_{\mathrm{b}}+\frac{K_{1}}{2}\left(c_{\mathrm{m}}^{2}-c_{\mathrm{b}}^{2}\right)+\frac{K_{2}}{3}\left(c_{\mathrm{m}}^{3}-c_{\mathrm{b}}^{3}\right)\right]
\end{aligned}
$$

Combining eqns. (41), (6) and (22) we obtain a relationship in which the permeate flux, $J_{v}$, is the single unknown parameter. In this way, $J_{v}$ can be calculated if the process conditions $\left(\Delta P, R_{\mathrm{m}}, c_{\mathrm{b}}\right.$ and $\left.k\right)$ and the physical properties of the solute-solvent system $(s$ and $D)$ are known.

Values for the mass transfer coefficient, $k$, are obtained in the following way. With the help of eqn. (17) the osmotic pressure difference over the membrane is calculated from the permeate flux data. The results are given in Table 1. From $\Delta \Pi_{\mathrm{m}}$ and the osmotic pressure data, the value of $c_{\mathrm{m}}$ is computed. The maximum value for $c_{\mathrm{m}}$ appears to be $0.364 \mathrm{~g} / \mathrm{ml}$ (Table 1) and since Dextran T70-water mixtures with concentrations up to $0.7 \mathrm{~g} / \mathrm{ml}$ are fluid, we conclude that in all experiments reported here no gel layer has been formed.

Using eqn. (6) and the $c_{\mathrm{m}}$ values given in Table 1, the apparent mass transfer coefficient $k^{\text {app }}$ can be calculated. In Fig. 8 this $k^{\text {app }}$ is compared with the mass transfer coefficient, $k$, as obtained from the Deissler equation for turbulent systems: 


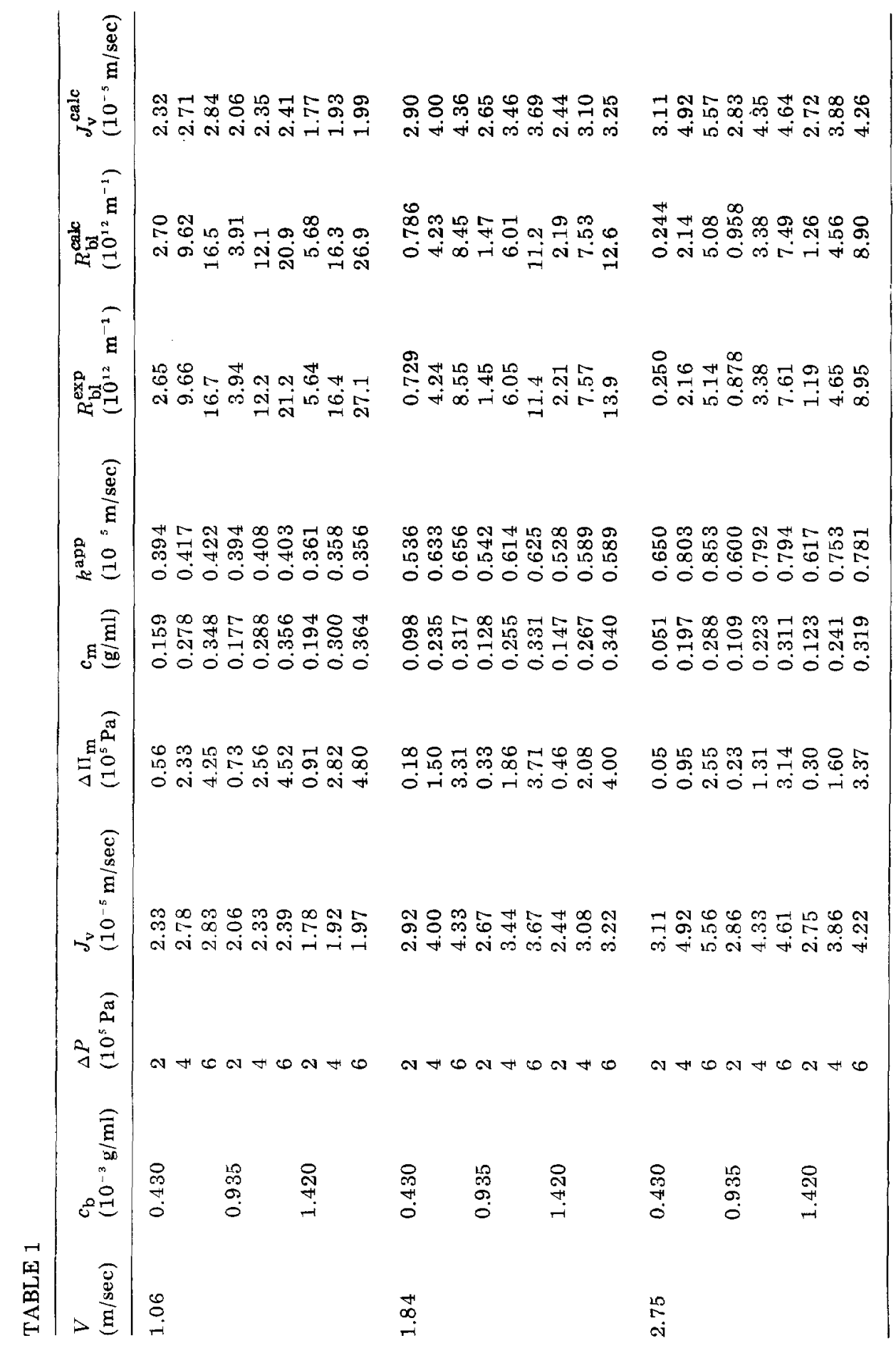


$k=0.023 \frac{D}{d_{\mathrm{h}}}\left(\frac{V d_{\mathrm{h}} \rho_{0}}{\eta_{0}}\right)^{0.875}\left(\frac{\eta_{0}}{\rho_{0} D}\right)^{0.25}$

where $d_{\mathrm{h}}=10.74 \mathrm{~mm}$ is the hydraulic diameler of the thin channel cell and $V$ is the axial bulk velocity. The diffusion coefficient used is the $D$ of the bulk solution, which is equal to $4 \times 10^{-11} \mathrm{~m}^{2} / \mathrm{sec}$, see Fig. 6 . The reason why eqn. (42) predicts too high values for the mass transfer coefficient is in our

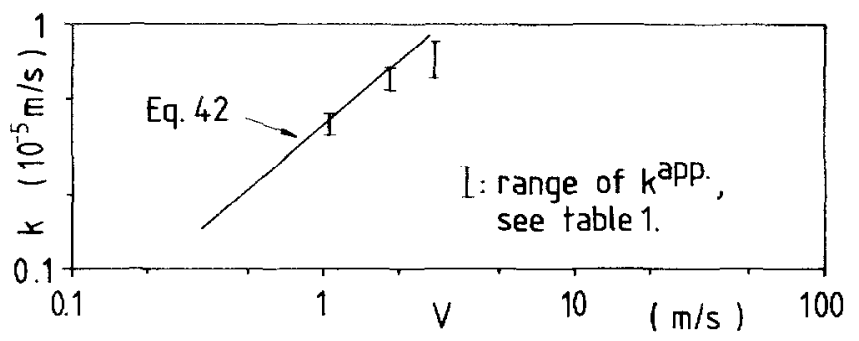

Fig. 8. Apparent and calculated mass transfer coefficients; - - Deissler equation.

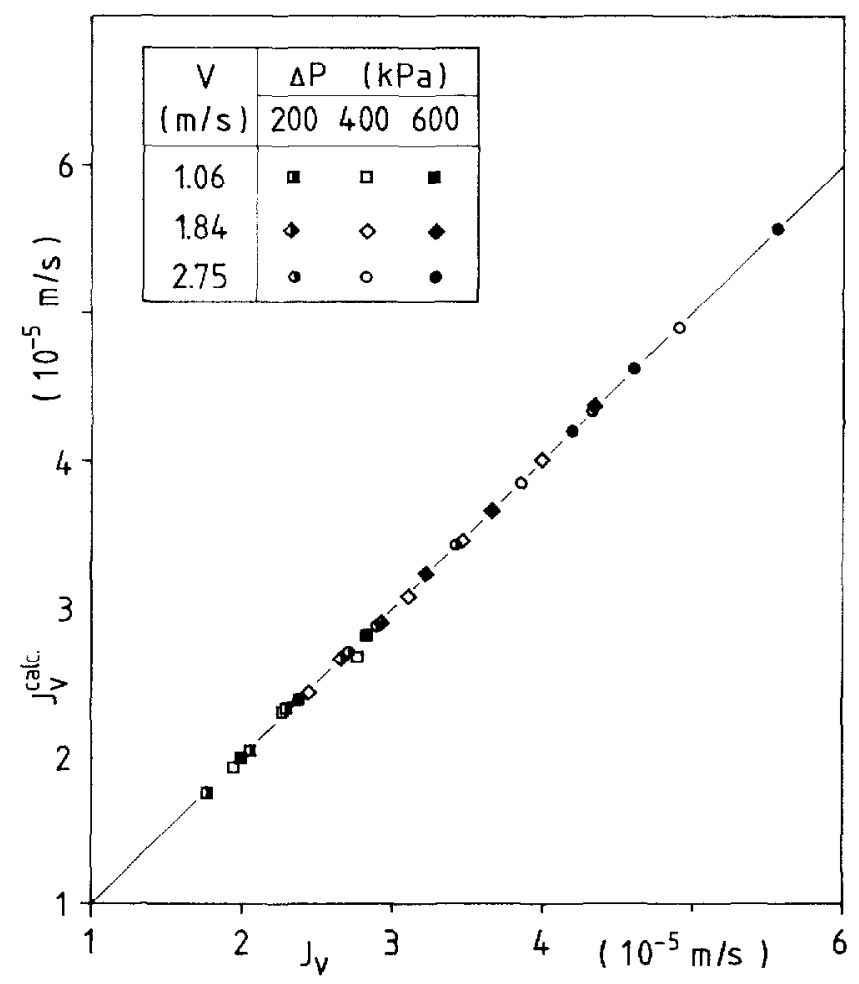

Fig. 9. Permeate flux calculated from eqns. (41), (6) and (22), $J_{v}^{\text {calc }}$, as function of experimental permeate flux, $J_{\mathrm{v}} ;-: J_{\mathrm{v}}^{\text {calc }}=J_{\mathrm{v}}$. 
opinion that no account has been made for the increase in viscosity in the boundary layer, nor for the effect of the permeate flux on the boundary layer.

The $k^{\text {app }}$ values are used to calculate the permeate flux and the result, $J_{v}^{\text {calc }}$, is displayed in the last column of Table 1 . The averaged value of $6 \times 10^{-11} \mathrm{~m}^{2} / \mathrm{sec}$ has been used in this calculation. In Fig. 9 the value of $J_{\mathrm{v}}^{\text {calc }}$ is plotted as a function of $J_{\mathrm{v}}$. The valuc of $J_{\mathrm{v}}$ is calculated using cqn. (22), thus neglecting the osmotic pressure of the bulk solution. The osmotic pressure data show that this approach is valid. As can be seen from Fig. 9, the correlation between $J_{\mathrm{v}}^{\text {calc }}$ and $J_{\mathrm{v}}$ is excellent. In the calculation procedure the values for the boundary layer resistance $R_{\mathrm{bl}}^{\text {calc }}$ are also obtained and these values are compared in Table 1 with $R_{\mathrm{bl}}^{\exp }$. The correlation is very good for $R_{\mathrm{bl}}$ values varying by more than two orders of magnitude, which in view of the close agreement of $J_{v}$ and $J_{v}^{\text {calc }}$ was expected. These results imply that the approach of calculating the resistance of the boundary layer with aid of the permeability of the Dextran molecules works well, as was already predicted in the theory section. In general, one can say that the stationary boundary layer in ultrafiltration can be seen as a diffusion-permeation equilibrium.

\section{Conclusions}

The permeate flux in ultrafiltration applications is smaller than the pure solvent flux due to the formation of a concentration polarization boundary layer. The effect of this concentrated but still fluid boundary layer can be represented in two different ways: (i) by a reduction of the driving force by a an osmotic pressure (the osmotic pressure model), and (ii) by an increase of the total resistance due to the resistance of the boundary layer (the resistance model). It is shown that these two approaches are essentially equivalent and that the resistance of the boundary layer can be computed with the solvent permeability of the macromolecular solute.

\section{List of symbols}

$A_{i} \quad$ coefficient in eqn. (27), $i=1,2,3\left(\mathrm{~Pa}-\mathrm{ml}^{i} / \mathrm{g}^{i}\right)$

$c_{0} \quad$ solvent concentration $(\mathrm{g} / \mathrm{ml})$

$c_{1} \quad$ solute concentration $(\mathrm{g} / \mathrm{ml})$

$c_{\mathrm{b}} \quad$ solute concentration in bulk $(\mathrm{g} / \mathrm{ml})$

$c_{\mathrm{m}} \quad$ solute concentration at membrane surface $(\mathrm{g} / \mathrm{ml})$

$d_{\mathrm{h}} \quad$ hydraulic diameter $(\mathrm{m})$

$D$ diffusion coefficient in volume-fixed frame $\left(\mathrm{m}^{2} / \mathrm{sec}\right)$

$D^{1} \quad$ diffusion coefficient in solute-fixed frame $\left(\mathrm{m}^{2} / \mathrm{sec}\right)$

$F_{0} \quad$ drag force on solvent $(\mathrm{N} / \mathrm{g})$

$F_{1} \quad$ drag force on solute $(\mathrm{N} / \mathrm{g})$

$J_{\mathrm{v}} \quad$ permeate volume flux $(\mathrm{m} / \mathrm{sec})$ 
$J_{v}^{\text {calc }} \quad J_{v}$ from eqns. $(6),(22)$ and $(41)(\mathrm{m} / \mathrm{sec})$

$k$ mass transfer coefficient $(\mathrm{m} / \mathrm{sec})$

$K_{i} \quad$ coefficient in eqn. $(30), i=1,2\left(\mathrm{ml}^{i} / \mathrm{g}^{i}\right)$

$M_{\mathrm{n}} \quad$ number-averaged molecular weight (dalton)

$M_{\mathrm{w}} \quad$ weight-averaged molecular weight (dalton)

$p \quad$ solvent permeability of the solute $\left(\mathrm{m}^{2}\right)$

$R \quad$ gas constant (J/mol-K)

$R_{\mathrm{b} 1} \quad$ resistance of boundary layer $\left(\mathrm{m}^{-1}\right)$

$R_{\mathrm{bl}}^{\mathrm{calc}}$

$R_{\mathrm{bl}}^{\mathrm{exp}}$

$R_{\mathrm{bl}}$ from eqns. (6), (22) and (41) $\left(\mathrm{m}^{-1}\right)$

$R_{\mathrm{m}}$

$s$

$R_{\mathrm{bl}}$ from eqn. (22) and flux data $\left(\mathrm{m}^{-1}\right)$

$s_{0} \quad s$ at infinite dilution (sec)

resistance of membrane $\left(\mathrm{m}^{-1}\right)$

$T$ temperature $(\mathrm{K})$ or $\left({ }^{\circ} \mathrm{C}\right)$

$U_{0} \quad$ velocity of solvent relative to the membrane $(\mathrm{m} / \mathrm{sec})$

$v_{0} \quad$ partial specific volume of the solvent $(\mathrm{ml} / \mathrm{g})$

$v_{1} \quad$ partial specific volume of the solute $(\mathrm{ml} / \mathrm{g})$

$V \quad$ axial bulk velocity $(\mathrm{m} / \mathrm{sec})$

$x \quad$ coordinate perpendicular to the membrane surface $(\mathrm{m})$

$\delta \quad$ thickness of boundary layer ( $\mathrm{m}$ )

$\Delta P \quad$ hydraulic pressure difference $(\mathrm{Pa})$

$\Delta \Pi \quad$ osmotic pressure difference $(\mathrm{Pa})$

$\Delta \Pi_{\mathrm{b}} \quad \Delta \Pi$ of bulk solution relative to permeate $(\mathrm{Pa})$

$\Delta \Pi_{\mathrm{b} 1} \quad \Delta \Pi$ over boundary layer $(\mathrm{Pa})$

$\Delta \Pi_{\mathrm{m}} \quad \Delta \Pi$ over membrane $(\mathrm{Pa})$

$\mu_{0} \quad$ chemical potential of the solvent $(\mathrm{N} / \mathrm{m}-\mathrm{g})$

$\mu_{0}^{c} \quad$ concentration part of $\mu_{0}(\mathrm{~N} / \mathrm{m}-\mathrm{g})$

$\mu_{1} \quad$ chemical potential of the solute $(\mathrm{N} / \mathrm{m}-\mathrm{g})$

$\mu_{i}^{c} \quad$ concentration part of $\mu_{1}(\mathrm{~N} / \mathrm{m}-\mathrm{g})$

$\eta_{0} \quad$ viscosity of the solvent $(\mathrm{Pa}-\mathrm{sec})$

$\rho \quad$ solution density $(\mathrm{g} / \mathrm{ml})$

$\rho_{0} \quad$ density of the solvent $(\mathrm{g} / \mathrm{ml})$

\section{References}

1 P.F. Mijnlieff and W.J.M. Jaspers, Solvent permeability of dissolved polymer material. Its direct determination from sedimentation experiments, Trans. Faraday Soc., 67 (1971) 61837.

2 S.R. de Groot and P. Mazur, Non-equilibrium Thermodynamics, North-Holland Publishing Company, Amsterdam, 1962, p. 251.

3 P. Dejmek, Concentration polarization in ultrafiltration of macromolecules, Ph.D. Thesis, Lund Institute of Technology, Lund, 1975.

4 M. Wales, Pressure drop across polarization layers in ultrafiltration, Amer. Chem. Soc., Symp. Ser., 154 (1981) 159.

5 H. Darcy, Les fontaines publiques de la ville de Dijon, 1856.

6 T. Svedberg and K.O. Pedersen, The Ultracentrifuge, Clarendon Press, Oxford, 1940 , 
7 M.E. McDonnell and A.M. Jamieson, Application of the porous-sphere hydrodynamic model to dilute polymer solutions, J. Polym. Sci., Polym. Phys. Ed., 18 (1980) 1781.

8 F.W. Altena, Ph.D. Thesis, Twente University of Technology, Enschede, 1982.

9 P.J. Flory, Principles of Polymer Chemistry, Cornell University Press, Ithaca, 1953, p. 531 .

10 W. Brown, P. Stilbs and R.M. Johnsen, Self-diffusion and sedimentation of Dextran in concentrated solutions, J. Polym. Sci., Polym. Phys. Ed., 20 (1982) 1771.

11 S. Nakao, J.G. Wijmans and C.A. Smolders, Resistance to the permeate flux in unstirred ultrafiltration. Part II. Dissolved macromolecular solutions, to be submitted to J. Membrane Sci.

12 F.R. Senti, N.N. Hellman, N.H. Ludwig, G.E. Babbcock, R. Tobin, C.A. Glass and B.L. Lamberts, Viscosity, sedimentation and light scattering properties of fractions of an acid-hydrolyzed Dextran, J. Polym. Sci., 17 (1955) 527.

13 A.G. Ogston and E.F. Woods, The sedimentation of some fractions of degraded Dextran, Trans. Faraday Soc., 50 (1954) 635.

14 J.W. Williams and W.M. Saunders, Size distribution analysis in plasma extender systems. II. Dextran, J. Phys. Chem., 58 (1954) 854.

15 M.J. Clifton, Polarisation de concentration dans divers procédés de séparation à membrane, Ph.D. Thesis, Université Paul Sabatier, Toulouse, France, 1982.

16 J.G. Wijmans, S. Nakao and C.A. Smolders, Flux limitation in ultrafiltration: Osmotic pressure model and gel layer model, J. Membrane Sci., 20 (1984) 115. 